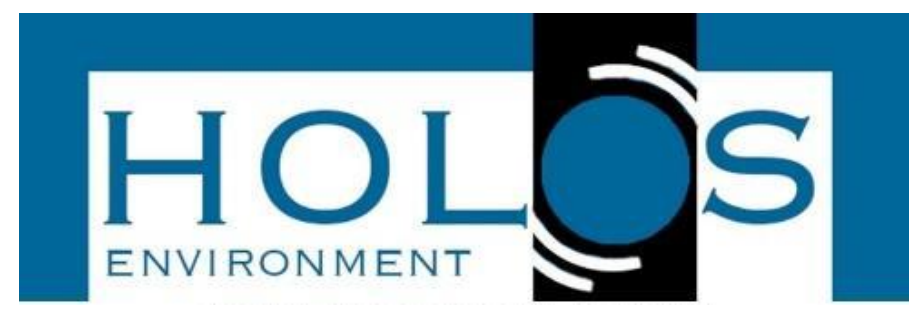

\title{
ANÁLISE DA SUSTENTABILIDADE E VIABILIDADE ECONÔMICA DE UMA PROPRIEDADE FAMILIAR EM PEDRO GOMES, MS
}

\section{SUSTAINABILITY AND ECONOMIC VIABILITY ANALYSIS OF A FAMILY PROPERTY IN PEDRO GOMES, MS}

\author{
Thalia da Silva Bezerra1; Poliana Ferreira da Costa1 ; Mylena dos Santos ${ }^{1}$
}

Artigo recebido em: 29/01/2020 e aceito para publicação em: 19/02/2020.

DOI: http://dx.doi.org/10.14295/holos.v20i2.12373

Resumo: O estudo ocorreu em uma propriedade de sistema de produção familiar no município de Pedro Gomes - MS, com o objetivo de analisar o grau de sustentabilidade da área através da aplicação de 55 indicadores, baseados no método MESMIS "Estrutura para Avaliação de Sistemas de Gestão de Recursos Naturais incorporando indicadores de Sustentabilidade", onde foi possível atribuir a pontuação por meio da somatória dos parâmetros escalados de 1 a 3 . Além disso, o estudo procurou apresentar a relação da viabilidade econômica da propriedade, evidenciando a rentabilidade do proprietário com o desenvolvimento das atividades realizadas, sendo assim feito uma comparação do preço dos produtos com o de mercado, no intuito de analisar a redução de gastos do proprietário pelo autoconsumo. Os resultados obtidos demonstram o alto nível de sustentabilidade da propriedade, tendo em vista que é caracterizada pela aplicação de práticas agroecológicas. Além de uma alta à viabilidade econômica, proporcionada pelo Sistema Agroflorestal, pela Heveicultura e demais atividades desenvolvidas na propriedade.

Palavras-chave: Práticas conservacionistas. Indicadores ambientais. Agricultura orgânica. Agroecologia.

\begin{abstract}
The study was carried out in a family production system property in the municipality of Pedro Gomes - MS, with the objective of analyzing the degree of sustainability of the area through the application of 55 indicators, based on the MESMIS method "Structure for Evaluation of Management Systems". Natural Resources incorporating Sustainability Indicators ", where it was possible to assign the score by summing the parameters scaled from 1 to 3 . In addition, the study sought to present the relationship of the economic viability of the property, highlighting the profitability of the owner with the development of the properties. activities performed, thus making a comparison of the price of the products with the market, in order to analyze the reduction of owner spending by self-consumption. The results show the high level of sustainability of the property, considering that it is characterized by the application of agroecological practices. In addition to a high economic viability, provided by the Agroforestry System, Heveicultura and other activities developed on the property.
\end{abstract}

Keywords: Conservationist practices. Environmental indicators. Organic agriculture. Agroecology.

\footnotetext{
${ }^{1}$ Universidade Estadual do Mato Grosso do Sul (UEMS). E-mails: (thaliabezerra15@gmail.com, polianacostagestao@gmail.com, mylenasantospg11@hotmail.com)
} 


\section{INTRODUÇÃO}

Nos últimos anos, o setor agrícola tem se fortalecido grandemente no Brasil, em razão de fatores como a intensa industrialização, aceleração do processo de urbanização e do avanço tecnológico (PEROBELLI, 2007). Além disso, deve-se considerar que o país apresenta características físicas e sociais distintas, contribuindo para uma maior diversificação de produção, distribuição de terras e organização social (GUILHOTO, 2007). Frente ao modelo capitalista, a agricultura tornou-se um processo baseado basicamente na produtividade em grande escala e na obtenção de lucro, sendo necessário amplos espaços para produção e utilização elevada de insumos, onde as questões ambientais são deixadas de lado (LIMA,2019; RIBEIRO; SANTOS e ALMEIDA, 2018; OLIVEIRA, 2007).

Segundo o Instituto de Pesquisa Ambiental da Amazônia (2017), a agricultura de maneira convencional vem crescendo cada vez mais no Cerrado, considerado o segundo maior Bioma do Brasil e que abriga grande parte da biodiversidade do planeta. De acordo com pesquisas realizadas pelo IPAM (2017), o bioma apresenta elevado índice de desmatamento, em função da expansão das práticas agrícolas e resultado da falta de planejamento do solo, o que coloca em risco a perca de sua vegetação nativa.

Em contrapartida, existem técnicas nesse meio que visam conciliar a produção, com a minimização de impactos sobre o meio ambiente, a viabilidade econômica e às questões sociais, caracterizando-as assim como práticas sustentáveis (EHLERS, 2017).

Uma das alternativas viáveis é a agricultura orgânica, considerada um processo produtivo que visa o cultivo por meio de técnicas que se adaptem às características naturais, assegurando o fornecimento de produtos orgânicos saudáveis e de qualidade, vez que nela não se faz uso de produtos químicos sintéticos (ROEL, 2002).

Paralelamente a agricultura orgânica Caporal e Costabeber (2004), destacam a técnica da agricultura ecológica ou agroecologia, a qual vai além da orgânica, pois além de substituir o uso de substâncias químicas, objetiva compreender os processos e relações ecológicas existentes no campo. Através da manipulação desses agroecossistemas, a produção torna-se mais viável e sustentável, vez que esta baseia-se na racionalização do uso de insumos externos, minimização dos impactos negativos ao meio ambiente e à sociedade, através da mudança de valores e atitudes em todo a cadeia de produção e manejo.

Neste mesmo viés, é trabalhada a agricultura familiar, um modelo social heterogêneo 
caracterizado pelo cultivo tradicional formado por grupo familiar, sendo eles os proprietários dos meios de produção, assumindo assim o trabalho e organizando os processos produtivos. Neste, a qualidade dos alimentos é superior ao do modelo convencional, pois é baseada em práticas sustentáveis, podendo ter foco tanto para sustento próprio, quanto para distribuição no mercado (LAMARCHE, 1993).

O presente trabalho teve como objetivo analisar a viabilidade do sistema de produção familiar de uma propriedade rural agroecológica no município de Pedro Gomes-MS, por meio de um levantamento socioeconômico, avaliar o grau de sustentabilidade, por meio da aplicação de indicadores ambientais, bem como calcular a rentabilidade do autoconsumo realizado na propriedade.

\section{MATERIAL E MÉTODOS}

Para a realização da pesquisa, utilizou-se o método de Estudo de Caso, e desenvolvido uma linha de investigação, através da coleta de informações, a fim de determinar conclusões a respeito do caso (VENTURA, 2007).

\subsection{Caracterização da área de estudo}

O estudo ocorreu no mês de outubro de 2018, em uma propriedade rural particular, de nome "Chácara Santa Luzia / Mamãe", localizada no município de Pedro Gomes - MS, entre as coordenadas geográficas $18^{\circ} 3^{\prime} 58$. 09" de latitude Sul e 54 $34^{\prime} 54.19^{\prime \prime}$ de longitude Oeste, como pode ser visto no mapa disposto na Figura 1, confeccionada com o Software Quantum Geographic Information System (QGIS), versão 2.18.12, também utilizado na confecção da Figura 2.

Segundo a classificação de Köppen, a região sofre influência do clima tropical úmido, do tipo AW, predominando o sub úmido, com estação chuvosa no verão e seca no inverno, com temperaturas médias acima de $20^{\circ} \mathrm{C}$ e abaixo de $24^{\circ} \mathrm{C}$. Nisso, o índice pluviométrico anual varia entre 1.200 a $1.500 \mathrm{~mm}$, com regimes de chuvas entre os meses de setembro a maio, e períodos secos entre junho a setembro (PREFEITURA MUNICIPAL DE PEDRO GOMES, MS). 
Figura 1 - Mapa de localização da área de estudo
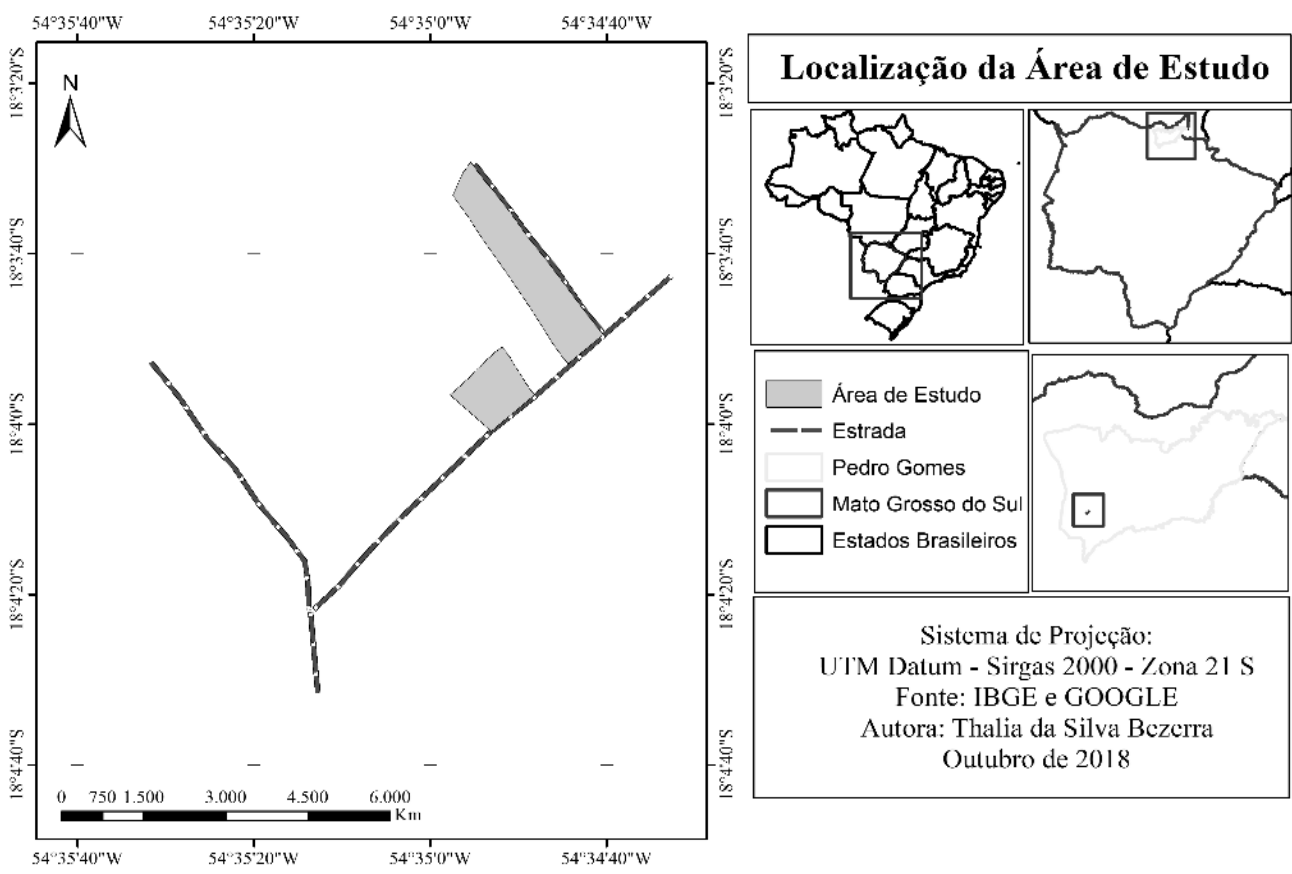

Fonte: Elaborado pelos autores

Com relação ao solo, a região é caracterizada pela predominância de Neossolos na porção leste, e nas demais a dominância de Latossolos Vermelho-Escuro e VermelhoAmarelo e em alguns pontos de Luvissolos. Com influência do Cerrado, o município é marcado pela predominância da agricultura, áreas de pastagem e várzeas (PREFEITURA MUNICIPAL DE PEDRO GOMES, MS).

\subsection{Produção e viabilidade econômica}

O trabalho procurou apresentar o sistema de produção de uma propriedade, que pode ser caracterizada como de agricultura familiar, pois somente familiares estão envolvidos nas atividades realizadas. Onde foi aplicado um questionário de informações gerais e uma tabela para listagem de todos os produtos produzidos, evidenciando o preço de venda dos mesmos e a quantidade utilizada para consumo próprio e comercialização. De acordo com esses dados, pôde ser feito posteriormente um comparativo dos produtos listados na propriedade, com o preço dos mesmos em um mercado local situado no município de Coxim-MS, no intuito de analisar a rentabilidade do sistema de produção.

É necessário ressaltar que o autoconsumo torna-se um lucro para a família, visto que as despesas são reduzidas com a manutenção alimentar advinda do sistema de produção. Dessa maneira, calculou-se o total de produtos destinados para o consumo 
próprio, sendo em seguida analisado o valor que seria gasto na compra desses produtos no mercado, caso não fossem produzidos na propriedade. Para a comparação dos dados, utilizou-se o mesmo método aplicado por Ahrens et al. (2007), sendo assim calculado:

1 - Receita Bruta = preço do produto $x$ quantidade vendida

2 - Margem Bruta = receita bruta - custos variáveis

3 - Lucro = receita bruta - custo total

4 - Relação benefício/custo = receita bruta / custo total

Logo: Custo Total $=$ custos fixos + custos variáveis

Nisso, os Custo Fixos referem-se ao valor relacionado à arrendamentos, aluguel, compra de maquinários e os custos variáveis ao uso de insumos para funcionamento das atividades na propriedade.

\subsection{Indicadores de sustentabilidade}

Para calcular o grau de sustentabilidade na área de estudo, utilizou-se como procedimento o método de MESMIS, "Marco de Evaluación de Sistemas de Manejo de Recursos Naturales incorporando Indicadores de Sustentabilidad", modelo aplicado no trabalho de Gallo et al. (2016), sendo proposto por Masera et al. (1999).

Sendo assim, a execução do método baseou-se na adaptação do modelo de Gallo et al. (2016), Masera et al. (1999), Santos e Cândido (2013) e Oliveira (2007), totalizando assim 55 indicadores, distribuídos em dimensões ambientais, econômicos, técnicoeconômicos, de manejo, sociais e político-institucional, e conservou-se os três parâmetros de Gallo et al. (2016), estabelecidos de 1 a 3, a fim de pontuar o grau de sustentabilidade, frente aos indicadores aplicados. A somatória dessas numerações, que apontam uma condição não desejável (1), regular (2) e desejável (3), tem como finalidade indicar o grau de sustentabilidade na área (VERONA, 2008).

Desse modo, a somatória dos parâmetros indica a situação da propriedade em análise, onde a pontuação igual ou menor que 60 demonstra que a área se encontra muito impactada; de 61 a 85 indica alteração no agroecossistema e a pontuação igual ou acima que 86 representa uma sustentabilidade próxima ao equilíbrio pleno da área (GUIMARÃES et al., 2015), citado por Gallo et al. (2016). 


\section{RESULTADOS E DISCUSSÂO}

\subsection{Produtividade}

Com 11 hectares, pôde-se evidenciar três principais atividades econômicas realizadas atualmente na área de estudo, propriedade de agricultura familiar, sendo elas a bovinocultura leiteira, a atividade de heveicultura em consórcio com o cultivo do abacaxi, e um Sistema Agroflorestal diverso em produção agroecológica, que também produz abacaxi.

Além do cultivo do abacaxi e da seringueira e da bovinocultura leiteira, a chácara apresenta outros sistemas de produção destinados tanto para a comercialização, quanto para a subsistência, sendo eles: a) horticultura: abóbora (Cucúrbita moschata), açafrão-daterra (cúrcuma longa), alface (Lactuca sativa), batata-doce (Ipomoea batatas), cebolinha (Allium schoenoprasum), coentro (Coriandrum sativum), couve (Brassica oleracea), gengibre (Zingiber officinale), jiló (Solanum aethiopicum 'Gilo group'), mandioca (Manihot esculenta), pimenta (Capsicum frutescens), quiabo (Abelmoschus esculentus), rúcula (Eruca vesicaria), salsa (Petroselinum crispum); b) fruticultura: acerola (Malpighia emarginata), araçá (Psidium cattleianum), banana (musa), coco (Cocos nucifera), fruta-doconde (Annona squamosa) goiaba (Psidium guajava), ingá (Inga edulis), jaca (Artocarpus heterophyllus), limão (Citrus limon), mamão (Carica papaya), manga (Mangifera indica), maracujá (Passiflora edulis), melancia (Citrullus lanatus), romã (Punica granatum); c) suinocultura; d) avicultura; e e) minhocultura.

Além disso, foram identificadas na propriedade espécies arbóreas, tais como o eucalipto, o cedro (Cedrus), jenipapo (Genipa americana), ipê (Tabebuia), angico-vermelho (Anadenanthera macrocarpa 'Benth' Brenan), tarumã (Vitex montevidensis), aroeiravermelha (Schinus terebinthifolius), embaúba (Cecropia), sangra d'água (Croton urucurana), cumbaru (Dipteryx odorata), jatobá (Hymenaea courbari), guarita (Astronium graveolens), guavira (Campomanesia adamantium), mangaba (Hancornia speciosa), algumas espécies frutíferas já citadas anteriormente como a mangueira, goiabeira, mamão, colorau e o ingá.

Diante dessa variedade, o mapa disposto na Figura 2 abaixo refere-se aos respectivos usos e ocupação do solo da propriedade em estudo, sendo assim caracterizado toda a sua porção. 
Figura 2 - Mapa de uso e ocupação do solo da propriedade em estudo.
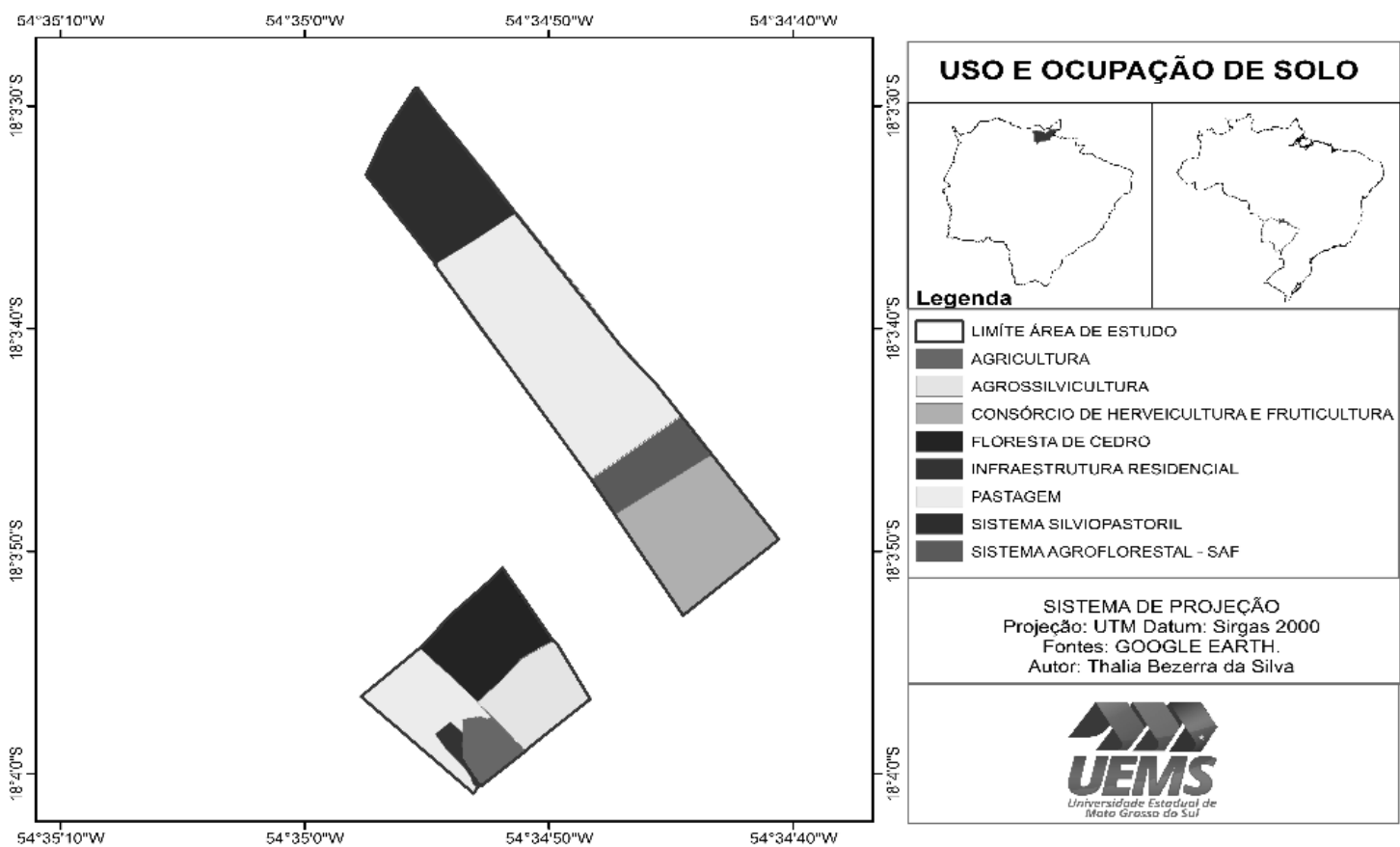

Fonte: Elaborado pelos autores

\subsection{Avaliação da viabilidade econômica da produção}

Por meio da entrevista realizada na propriedade, obteve-se uma relação dos produtos existentes na mesma, utilizados tanto para comercialização, quanto para autoconsumo. A área é composta por uma variedade de produção agrícola, como espécies frutíferas, leguminosas e verduras, assim como a criação de animais, produção de compostos orgânicos e a extração da borracha com o cultivo da seringueira, totalizando 36 itens dispostos na Tabela 1 abaixo.

Diante dos dados dispostos na Tabela 1, percebe-se que os produtos mais comercializados na propriedade são o abacaxi, a borracha proveniente da seringa, o leite e a mandioca, os quais destacam-se pelo aumento da renda obtida na propriedade.

Por meio do levantamento realizado na propriedade em estudo, pôde-se obter o valor total da renda do proprietário em relação às vendas dos produtos, sendo em torno de $R \$$ 4.403,00 mensal, de acordo com o preço e quantidade dos produtos vendidos pelo mesmo. Os preços consultados no mercado local, demonstra a quantia que o proprietário teria que desembolsar para consumir os mesmos produtos, sendo em média $R \$ 2.368,13$ de economia no mês, caracterizando assim a viabilidade do seu sistema de produção. 
Tabela 1- Receitas obtidas com produção para venda e autoconsumo

\begin{tabular}{|c|c|c|c|c|c|}
\hline \multirow[t]{2}{*}{ Produto } & \multirow[t]{2}{*}{ Unidade } & \multicolumn{2}{|c|}{ Venda } & \multicolumn{2}{|c|}{ Autoconsumo } \\
\hline & & Qtd. & Preço & Qtd. & $\begin{array}{l}\text { Preço de } \\
\text { Mercado }\end{array}$ \\
\hline Abacaxi & UN & 200 & $\mathrm{R} \$ 3,00$ & 8 & $\mathrm{R} \$ 7,49$ \\
\hline Abóbora & UN & 50 & $R \$ 5,00$ & 15 & $\mathrm{R} \$ 2,99$ \\
\hline Açafrão & KG & 0 & $\mathrm{R} \$ 0,00$ & 0,083 & $R \$ 10,99$ \\
\hline $\begin{array}{c}\text { Adubo } \\
\text { orgânico } \\
\text { (esterco de } \\
\text { galinha) }\end{array}$ & $K G$ & 20 & $\mathrm{R} \$ 1,00$ & 0 & $\mathrm{R} \$ 7,00$ \\
\hline $\begin{array}{c}\text { Adubo } \\
\text { orgânico } \\
\text { (esterco } \\
\text { bovino) }\end{array}$ & SACO & 30 & $\mathrm{R} \$ 10,00$ & 20 & $\mathrm{R} \$ 18,00$ \\
\hline Alface & MAÇO & 0 & $\mathrm{R} \$ 0,00$ & 20 & $R \$ 2,49$ \\
\hline $\begin{array}{c}\text { Banana da } \\
\text { terra }\end{array}$ & $K G$ & 100 & $\mathrm{R} \$ 5,00$ & 40 & $R \$ 5,99$ \\
\hline $\begin{array}{c}\text { Banha de } \\
\text { porco (gordura } \\
\text { animal) }\end{array}$ & $\mathrm{L}$ & 4 & $R \$ 16,00$ & 3 & $\mathrm{R} \$ 8,49$ \\
\hline Batata-doce & KG & 0 & $\mathrm{R} \$ 0,00$ & 1,75 & $R \$ 3,49$ \\
\hline Borracha & $K G$ & 400 & $R \$ 2,50$ & 0 & $\mathrm{R} \$ 0,00$ \\
\hline Seringueira & & & & & \\
\hline Gado & UN & 0,3 & $R \$ 1.000,00$ & 0,16 & $\mathrm{R} \$ 1.300,00$ \\
\hline Carne suína & KG & 0 & $R \$ 0,00$ & 8 & $\mathrm{R} \$ 8,49$ \\
\hline Cebolinha & MAÇO & 0 & $\mathrm{R} \$ 0,00$ & 30 & $R \$ 2,09$ \\
\hline Côco & UM & 0 & $\mathrm{R} \$ 0,00$ & 50 & $\mathrm{R} \$ 8,49$ \\
\hline Coentro & MAÇO & 0 & $\mathrm{R} \$ 0,00$ & 20 & $R \$ 2,09$ \\
\hline Colorau & $G$ & 0 & $\mathrm{R} \$ 0,00$ & 125 & $\mathrm{R} \$ 0,03$ \\
\hline Couve & MAÇO & 0 & $\mathrm{R} \$ 0,00$ & 20 & $R \$ 3,29$ \\
\hline $\begin{array}{l}\text { Farinha de } \\
\text { mandioca }\end{array}$ & KG & 25 & $\mathrm{R} \$ 5,00$ & 0,4 & $R \$ 5,99$ \\
\hline $\begin{array}{c}\text { Carne de } \\
\text { Frango }\end{array}$ & $K G$ & 0 & $\mathrm{R} \$ 0,00$ & 4 & $\mathrm{R} \$ 7,29$ \\
\hline Gengibre & KG & 0 & $\mathrm{R} \$ 0,00$ & 0,25 & $R \$ 5,99$ \\
\hline Goiaba & KG & 0 & $\mathrm{R} \$ 0,00$ & 0,5 & $\mathrm{R} \$ 7,99$ \\
\hline $\begin{array}{l}\text { Húmus } \\
\text { minhoca }\end{array}$ & PCT & 3 & $\mathrm{R} \$ 5,00$ & 0 & $\mathrm{R} \$ 9,90$ \\
\hline Jiló & $K G$ & 0 & $\mathrm{R} \$ 0,00$ & 5 & $\mathrm{R} \$ 4,99$ \\
\hline Leite & $\mathrm{L}$ & 100 & $\mathrm{R} \$ 1,19$ & 30 & $\mathrm{R} \$ 3,89$ \\
\hline $\begin{array}{l}\text { Lenha } \\
\text { eucalipto }\end{array}$ & $M$ & 3 & $\mathrm{R} \$ 60,00$ & 2 & $\mathrm{R} \$ 62,00$ \\
\hline Limão & KG & 0 & $\mathrm{R} \$ 0,00$ & 10 & $\mathrm{R} \$ 8,99$ \\
\hline Mamão & UN & 0 & $\mathrm{R} \$ 0,00$ & 5 & $R \$ 2,99$ \\
\hline Mandioca & $K G$ & 100 & $\mathrm{R} \$ 2,00$ & 15 & $\mathrm{R} \$ 2,29$ \\
\hline Manga & $K G$ & 0 & $\mathrm{R} \$ 0,00$ & 1,6 & $R \$ 3,79$ \\
\hline Maracujá & $K G$ & 20 & $R \$ 5,00$ & 5 & $\mathrm{R} \$ 8,99$ \\
\hline Melância & UN & 84 & $\mathrm{R} \$ 7,50$ & 0,25 & $R \$ 1,49$ \\
\hline Ovo & DZ & 0 & $\mathrm{R} \$ 0,00$ & 16 & $R \$ 5,49$ \\
\hline Pimenta & $K G$ & 0 & $\mathrm{R} \$ 0,00$ & 0,1 & $\mathrm{R} \$ 4,99$ \\
\hline Quiabo & KG & 0 & $\mathrm{R} \$ 0,00$ & 5 & $\mathrm{R} \$ 4,99$ \\
\hline Rúcula & MAÇO & 0 & $R \$ 0,00$ & 15 & $\mathrm{R} \$ 2,49$ \\
\hline $\begin{array}{l}\text { Salsa } \\
\text { Total }\end{array}$ & MAÇO & 0 & $\begin{array}{c}R \$ 0,00 \\
\mathbf{R} \$ \mathbf{4 . 4 0 3 , 0 0}\end{array}$ & 30 & $\begin{array}{l}\mathrm{R} \$ 2,09 \\
\mathbf{R} \$ \mathbf{2 . 3 6 8 , 1 3}\end{array}$ \\
\hline
\end{tabular}

Fonte: Elaborado pelos autores 
É necessário ressaltar que alguns dos produtos existentes na propriedade não foram encontrados disponíveis no mercado, como é o caso da acerola, da araçá, da fruta-doconde, do ingá e da jaca, os quais possuem apenas fins de consumo à família, sendo assim ocultados da presente Tabela.

Cabe dizer, que os produtos além de destinados a associações vinculadas à propriedade, são também distribuídos para a comunidade local, seja em escolas, para moradores da região e mercados, onde frequentemente realizam permutas entre os alimentos de interesse.

No que se diz respeito aos custos, a propriedade é ausente de custos fixos, ou seja, não há despesas com pagamento de aluguel, maquinários ou outros meios. Com relação aos custos variáveis, considerou alguns quesitos, como a compra de produtos utilizados para tratamento de saúde dos gados, a reposição de combustível e a manutenção realizada no meio de transporte para distribuição dos produtos, como mostra a Tabela 2 abaixo.

Tabela 2 - Custos fixos e variáveis no sistema de produção

\begin{tabular}{cccc}
\hline \multicolumn{2}{c}{ Fixos } & \multicolumn{3}{c}{ Variáveis } \\
\hline Descrição & Valor & Descrição & Valor \\
- & - & Carrapaticida / Inseticida & $\mathrm{R} \$ 20,00$ \\
- & - & Combustível & $\mathrm{R} \$ 250,00$ \\
- & - & Manutenção Caminhonete & $\mathrm{R} \$ 300,00$ \\
Total & $\mathrm{R} \$ 0,00$ & Total & $\mathrm{R} \$ 570,00$ \\
\hline
\end{tabular}

Fonte: Elaborado pelos autores

Pelo total do valor obtido dos custos na propriedade, subentende-se que a relação custo-benefício é positiva, uma vez que $\mathrm{R} \$ 570,00$ é considerado baixo, se comparado às receitas adquiridas pelo proprietário. Em entrevista, o proprietário relatou que os gastos foram maiores no início da implantação dos sistemas de produção, tendo como custo a compra de 4 cabeças de gado há 20 anos atrás, no valor de $R \$ 742,00$ na época e a compra das seringueiras, que foram adquiridas pelo preço de $\mathrm{R} \$ 4.500,00$ há 10 anos atrás. Quanto ao cultivo de abacaxi, o proprietário relatou ainda que no início do sistema, recebeu de doações algumas mudas, e as multiplicou posteriormente, produzindo novas mudas. Com o desenvolvimento do sistema, o proprietário atualmente possui em sua propriedade 7 vacas leiteiras, 800 seringueiras e 30.000 plantas de abacaxi. Sendo assim, obteve-se os valores totais monetários da propriedade, no que se refere à receita bruta, aos custos, a 
margem bruta e ao lucro adquirido pelo desenvolvimento das atividades, dispostos na Figura 3 a seguir.

Figura 3 - Totalidade dos valores econômicos apresentados no sistema de produção da propriedade de agricultura familiar

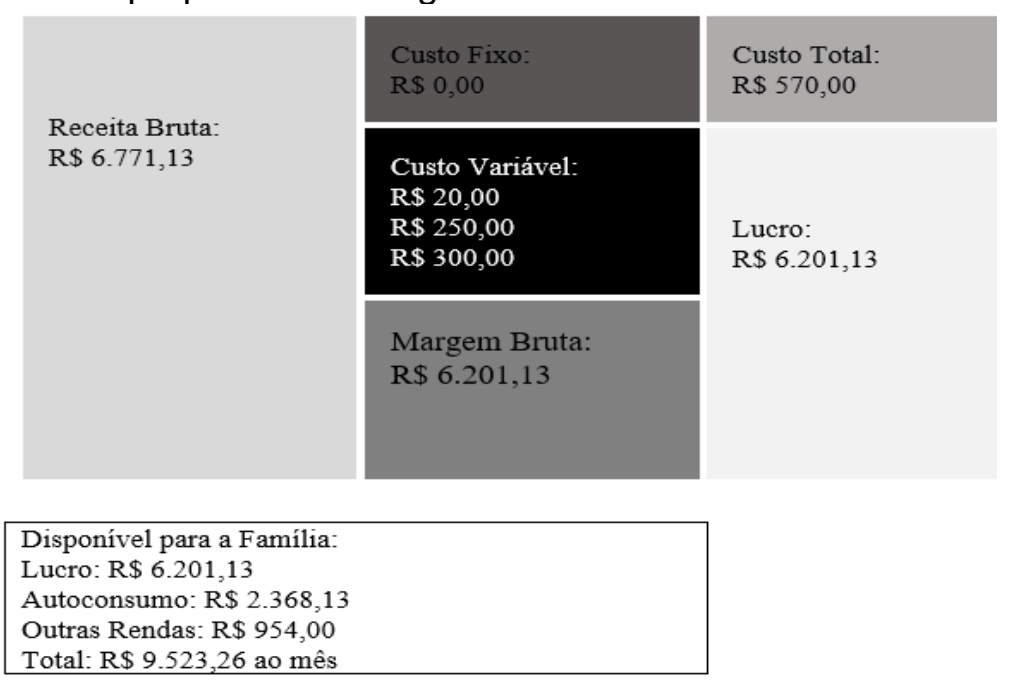

A receita bruta da propriedade, que corresponde à relação do preço dos produtos com a quantidade vendida apresentou-se significativamente favorável com $R \$ 6.771,13$, considerando a obtenção somente pelas atividades executadas na propriedade.

Pelo fato dos gastos existentes serem mínimos, com a subtração da receita bruta pelos custos totais, a lucratividade obtida pelo proprietário é considerada elevada, com total de $R$ \$ 6.201,13 disponíveis mensalmente para a família, o mesmo se aplica à margem bruta, visto que a propriedade não apresenta custo fixos.

Com isso, a somatória do valor do lucro, do autoconsumo e da aposentadoria da esposa do proprietário resultou em um total de $R \$ 9.523,26$ mensal, caracterizando assim a boa rentabilidade do sistema de produção.

Em um estudo semelhante, Ahrens et al. (2007) verificaram que em uma propriedade localizada em União da Vitória-PR, apresentou benefícios pelo fato das práticas agroecológicas adotadas em seu sistema de agricultura familiar, como o rendimento econômico e a sustentabilidade da propriedade, que também é baseada no autoconsumo e na comercialização dos produtos.

Como perspectivas futuras, o proprietário pretende implantar novas técnicas e espécies que contribuam para o avanço funcional e econômico da propriedade. Nisso, objetiva-se introduzir algumas espécies como o Açaí, a Laranja e a Pitaia, bem como o sistema de plantio direto na palha para a espécie da melancia, que consiste na forma de manejo do solo, onde os restos culturais, e nesse caso a palha, são depositados na 
superfície, tendo como princípio o mínimo revolvimento do solo e a rotação de culturas, visando aumentar a produtividade e melhorar as condições do ambiente, tornando assim a propriedade ainda mais sustentável (REIS et al., 2007).

Segundo Borghi et al. (2008), esse sistema é considerado vantajoso, vez que em seu experimento a distribuição espacial do milho e da Brachiaria brizantha foram analisados no sistema plantio direto na palha. Como resultados, os autores obtiveram a diminuição da densidade de ervas daninhas que estavam em consórcio com as culturas, proporcionando um índice de $95 \%$ de controle, o que demonstra a viabilidade de adotar esse sistema na propriedade em estudo.

\subsection{Indicadores de sustentabilidade}

De maneira geral, os indicadores que compõem a Tabela 3 abaixo, auxiliam na percepção sustentável que a área apresenta, visto que o termo engloba um conjunto de aspectos não somente ambientais, mas também econômicos e sociais, assim como seus subconjuntos incorporados na mesma.

No âmbito ambiental, pôde-se verificar que a propriedade é caracterizada por apresentar grande diversidade de culturas, enquadrando-se no parâmetro 3, como mostra a tabela acima, visto que a atividade agrícola é a principal fonte de renda da propriedade, considerando a comercialização e o autoconsumo.

Dos 55 indicadores dispostos na tabela, 26 compreendem o parâmetro 3, como é o caso dos resíduos orgânicos de cozinha, onde é realizado o reaproveitamento destes através do processo de compostagem, considerado uma alternativa de tratamento biológico que resulta na formação de adubo orgânico (WANGEN; FREITAS, 2010). Com relação ao parâmetro 2, 16 dos indicadores enquadram-se no mesmo, como por exemplo, a agregação de valor realizada em parte da produção, tendo em vista que as práticas agroecológicas contribuem para a melhor imagem e valoração do produto e da propriedade em que é adotada. Por último, 14 indicadores compreendem o parâmetro 1, como por exemplo, a não formação técnica do proprietário.

À vista disso, o consórcio de culturas é considerado uma das práticas predominantes na área, sendo realizado em todos os sistemas. Esse procedimento consiste no cultivo de duas ou mais espécies em uma mesma área (MONTEZANO e PEIL, 2006), o que proporciona o aumento da renda do produtor, bem como a diminuição da erosão do solo e no controle de ervas daninhas (TEIXEIRA et al., 2005). 
Tabela 3 - Indicadores ambientais, econômicos, técnico-econômicos, de manejo, social e políticoinstitucional, para verificação do grau de sustentabilidade do sistema de produção familiar

\begin{tabular}{|c|c|c|c|c|}
\hline Aspectos & Indicadores & & Parâmetros & \\
\hline & Possui Área de & $\begin{array}{c}1 \\
\text { Não possui }\end{array}$ & $\begin{array}{ll}<50 \% & 2\end{array}$ & $\begin{array}{c}3 \\
>50 \% \text { protegidas }\end{array}$ \\
\hline & $\begin{array}{l}\text { Preservação Permanente } \\
\text { ou Reserva Legal }\end{array}$ & & & \\
\hline & Animais silvestres & Não há população & Pouca população & Alta população \\
\hline & Água p/ agricultura & Não tratada & Filtrada & Tratada \\
\hline & Insumos & Mineral & Mineral+org. & Orgânico \\
\hline & Uso de adubação verde & Não faz & Esporadicamente & Faz com frequência \\
\hline & Rotação de culturas & Não faz & Alguns sistemas & $\begin{array}{l}\text { Faz em todos os } \\
\text { sistemas }\end{array}$ \\
\hline & Diversidade de culturas & Baixa & Média & Alta \\
\hline & $\begin{array}{ll}\text { Consorciação } & \text { de } \\
\text { culturas/plantas } & \end{array}$ & Não faz & Em um dos sistemas & $\begin{array}{l}\text { Faz em todos os } \\
\text { sistemas }\end{array}$ \\
\hline & Compactação do solo & $\begin{array}{l}\text { Grande parte da } \\
\text { área }\end{array}$ & $\begin{array}{l}\text { Pequena parte da } \\
\text { área }\end{array}$ & Não tem \\
\hline \multirow[t]{18}{*}{ Ambiental } & Quebra ventos & Não tem & $\begin{array}{l}\text { Há nas áreas de } \\
\text { cultivo }\end{array}$ & Em toda a área \\
\hline & Cobertura do solo & Solo exposto & Apenas c/ cultivos & $\begin{array}{l}\text { Cobertura em todo } \\
\text { o ano }\end{array}$ \\
\hline & Defensivos Químicos & Todas as culturas & Grandes culturas & $\begin{array}{l}\text { Não faz/defensivos } \\
\text { orgânicos }\end{array}$ \\
\hline & Fertilizantes químicos & Todas as culturas & Grandes culturas & Não faz uso \\
\hline & $\begin{array}{l}\text { Práticas de conservação } \\
\text { do solo }\end{array}$ & Não faz & Algumas áreas & Todas as áreas \\
\hline & Processo erosivo & Grandes áreas & Pequenas áreas, & Não tem \\
\hline & $\begin{array}{l}\text { Controle de plantas } \\
\text { espontâneas }\end{array}$ & Herbicida & Capina + herbicida & Cobertura +capina \\
\hline & $\begin{array}{l}\text { Implementos agrícolas } \\
\text { usados }\end{array}$ & Modo intensivo & Manual & Quando necessário \\
\hline & $\begin{array}{l}\text { Controle natural de pragas } \\
\text { e doenças }\end{array}$ & Não realiza & Algumas culturas & Todas as culturas \\
\hline & $\begin{array}{l}\text { Resíduos orgânicos da } \\
\text { cozinha }\end{array}$ & Queimado & Lixo comum & Compostagem \\
\hline & Óleo residual & Pia & Armazenamento & Reciclado \\
\hline & $\begin{array}{ll}\text { Aproveitamento } & \text { de } \\
\text { resíduos das culturas } & \end{array}$ & Não se faz & Alguns materiais & Sempre se faz \\
\hline & Áreas degradadas & Várias & Algumas & Não há \\
\hline & $\begin{array}{l}\text { Presença de atividade } \\
\text { agrícola }\end{array}$ & Não possui & $<50 \%$ & $>50 \%$ \\
\hline & Propriedade onde reside & Alugada & Parente & Própria \\
\hline & Agregação de valor & Não realiza & $\begin{array}{l}\text { Realiza em parte da } \\
\text { produção }\end{array}$ & $\begin{array}{l}\text { Realiza em toda a } \\
\text { produção }\end{array}$ \\
\hline & $\begin{array}{l}\text { Possui outras fontes de } \\
\text { renda }\end{array}$ & Não & Sim/sazonal & Sim, aposentadoria \\
\hline & $\begin{array}{l}\text { Controle dos custos das } \\
\text { atividades }\end{array}$ & Não & Esporadicamente & Sim \\
\hline \multirow[t]{4}{*}{ Econômico } & Acesso ao PRONAF & Nunca acessou & Pretende acessar & Já acessou \\
\hline & $\begin{array}{l}\text { Comercialização de } \\
\text { produtos }\end{array}$ & Com intermediário & $\begin{array}{l}\text { Intermediário } \\
\text { +venda direta }\end{array}$ & $\begin{array}{l}\text { Venda direta (feiras, } \\
\text { local de produção, } \\
\text { etc) }\end{array}$ \\
\hline & Infra-estrutura & Não adequada & Precisa & Adequada \\
\hline & Mão de obra terceirizada & $\begin{array}{l}\text { Para todas as } \\
\text { atividades }\end{array}$ & $\begin{array}{l}\text { Em algumas } \\
\text { atividades }\end{array}$ & Não há \\
\hline
\end{tabular}


Tabela 3 - Indicadores ambientais, econômicos, técnico-econômicos, de manejo, social e políticoinstitucional, para verificação do grau de sustentabilidade do sistema de produção familiar

\begin{tabular}{|c|c|c|c|c|}
\hline Aspectos & Indicadores & & Parâmetros & \\
\hline \multirow{7}{*}{$\begin{array}{l}\text { Técnico- } \\
\text { econômico }\end{array}$} & Assistência técnica & Raramente & Esporadicamente & Frequentemente \\
\hline & $\begin{array}{lr}\text { Participa } & \text { de } \\
\text { Cooperativas } & \text { e/ou }\end{array}$ & Não participa & Pretende participar & Participa \\
\hline & $\begin{array}{l}\text { Interdependência do } \\
\text { sistema }\end{array}$ & Não existe & Parcialmente & Existe \\
\hline & $\begin{array}{l}\text { Tempo de trabalho } \\
\text { com a agricultura }\end{array}$ & 1 ano & 4 anos & Mais de 5 anos \\
\hline & $\begin{array}{l}\text { Tempo de adoção de } \\
\text { práticas } \\
\text { agroecológicas }\end{array}$ & 1 ano & 2 anos & Mais de 4 anos \\
\hline & $\begin{array}{ll}\text { Produtos } & \text { recebem } \\
\text { certificação } & \end{array}$ & Não recebe & Pretende receber & Recebe \\
\hline & $\begin{array}{l}\text { Treinamento } \mathrm{p} / \\
\text { trabalhar com a } \\
\text { agricultura orgânica }\end{array}$ & Não faz & Esporadicamente & $\begin{array}{l}\text { Faz } \\
\text { periodicamente }\end{array}$ \\
\hline \multirow[t]{8}{*}{ Manejo } & $\begin{array}{l}\text { Mecanização de tração } \\
\text { animal }\end{array}$ & Não utiliza & Já utilizou & Utiliza \\
\hline & $\begin{array}{l}\text { Uso de adubação } \\
\text { orgânica (esterco) }\end{array}$ & Não faz & Esporadicamente & $\begin{array}{l}\text { Faz com } \\
\text { frequência }\end{array}$ \\
\hline & $\begin{array}{l}\text { Uso de semente } \\
\text { selecionada }\end{array}$ & Não faz & Algumas culturas & Todas as culturas \\
\hline & $\begin{array}{l}\text { Controle de invasores } \\
\text { com práticas orgânicas }\end{array}$ & Não realiza & Esporadicamente & $\begin{array}{l}\text { Realiza } \\
\text { periodicamente }\end{array}$ \\
\hline & Utiliza estufa & Não utiliza & Já utilizou & Utiliza \\
\hline & Irrigação & Não faz & Algumas culturas & Todas as culturas \\
\hline & $\begin{array}{l}\text { Qualidade de vida } \\
\text { Escolaridade }\end{array}$ & $\begin{array}{l}\text { Ruim } \\
\text { Analfabeto }\end{array}$ & $\begin{array}{l}\text { Regular } \\
\text { Ensino }\end{array}$ & $\begin{array}{l}\text { Boa } \\
\text { Ensino }\end{array}$ \\
\hline & $\begin{array}{l}\text { Água p/ consumo } \\
\text { humano }\end{array}$ & Não tratada & $\begin{array}{l}\text { fundamental } \\
\text { Filtrada }\end{array}$ & $\begin{array}{l}\text { médio/Graduação } \\
\text { Tratada }\end{array}$ \\
\hline \multirow[t]{5}{*}{ Social } & Uso de EPI & Não faz & Parcialmente & $\begin{array}{l}\text { Todas } \\
\text { atividades }\end{array}$ \\
\hline & Acesso a saúde & Difícil & Regular & Fácil \\
\hline & Esgoto & Ambiente & Fossa & Tratado \\
\hline & $\begin{array}{l}\text { Reciclagem de lixo } \\
\text { Qualidade das } \\
\text { estradas }\end{array}$ & $\begin{array}{l}\text { Não faz } \\
\text { Qualidade } \\
\text { baixa }\end{array}$ & $\begin{array}{l}>10<60 \% \\
\text { Qualidade média }\end{array}$ & $\begin{array}{l}>60 \% \\
\text { Boa qualidade }\end{array}$ \\
\hline & $\begin{array}{l}\text { Assistência técnica do } \\
\text { governo (federal, } \\
\text { estadual ou municipal) }\end{array}$ & Não recebe & Pretende procurar & Recebe \\
\hline \multirow{3}{*}{$\begin{array}{c}\text { Político- } \\
\text { institucional }\end{array}$} & Fez cursos para & Não fez & Pretende fazer & Já fez/faz \\
\hline & $\begin{array}{l}\text { trabalhar com a } \\
\text { agricultura orgânica }\end{array}$ & & & \\
\hline & $\begin{array}{l}\text { Pretende } \\
\text { produzindo } \\
\text { orgânicos }\end{array}$ & Não pretende & Temporariamente & $\begin{array}{l}\text { Sim, por muito } \\
\text { tempo }\end{array}$ \\
\hline
\end{tabular}

Fonte: adaptado de Gallo et al. (2016), Santos e Cândido (2013), Masera et al. (1999) e Oliveira (2007).

*As palavras em negrito correspondem aos parâmetros da propriedade em estudo.

Na propriedade os cultivos também são feitos em Sistemas Agroflorestais (SAFs), que correspondem na consorciação entre espécies arbóreas e animais e/ou culturas agrícolas em uma mesma área simultaneamente ou temporal, na propriedade o sistema é 
formado pela combinação entre a seringueira, abacaxi, espécies arbóreas nativas, abóbora, batata doce, entre outros, proporcionando assim inúmeras vantagens à área, como a melhoria da fertilidade do solo, melhorando a variedade da produção elevando a renda familiar, o menor custo de implantação e manutenção, etc. (EMBRAPA, 2004).

Um estudo realizado por Rodrigues et al. (2007), na região Pontal do Paranapanema - SP, especificamente no Assentamento Santa Zélia no município de Teodoro Sampaio, é exemplo dessas vantagens, uma vez que se baseou na implantação dos SAF's de diferentes culturas em seis famílias e todas apresentaram valores econômicos positivos. Para eles, a viabilidade econômica depende do manejo adequado da área, bem como da estipulação de preços para venda no mercado.

Neste contexto, a questão econômica da propriedade tem como base a produção agrícola, sendo responsável pela maior parte do faturamento mensal do proprietário. Entretanto, a tabela evidencia a independência na realização das atividades pelo proprietário, o qual não possui mão-de-obra terceirizada, assim como nenhuma assistência técnica externa.

Em entrevista, o proprietário relatou nunca ter acessado o Programa Nacional de Fortalecimento da Agricultura familiar (PRONAF), instrumento voltado para o incentivo financeiro e humano aos pequenos produtores rurais. Desse modo, o proprietário explicou que não mantém interesse em fazer parte de nenhum programa do governo, uma vez que pôde-se observar certa resistência por parte do mesmo no que se diz respeito a esses incentivos, e nisso pretende assim continuar com o sistema de produção seguindo o modelo desenvolvido.

Quanto ao aspecto técnico-econômico, o proprietário incorporou em suas atividades procedimentos agroecológicos, característica que atribui valor ao seu sistema. Em relação ao manejo, o mesmo apontou a preferência pela realização de práticas orgânicas em seus plantios, porém, em últimos casos o agrotóxico tem sido utilizado em quantidade mínima, se comparado ao modelo convencional. No entanto, ainda objetiva excluir a utilização de substâncias químicas, até que se torne zero.

Dessa maneira, o controle de invasores em seus cultivos é feito em grande parte por meio de práticas orgânicas e ecológicas, uma vez que uma das principais ameaças é o cupim, causando significativos prejuízos às espécies cultivadas. Para amenizar essa situação, o proprietário deposita periodicamente cinzas de madeira ao redor das culturas, repelindo grande parte dos insetos. Outra solução encontrada pelo proprietário foi a 
pulverização de extrato concentrado de fumo nos plantios, contribuindo tanto para o controle de pragas, como de doenças.

Em se tratando da adubagem dos plantios, segundo o proprietário a utilização de esterco e do húmus de minhoca tem se tornado vantajosa para o desenvolvimento das espécies, sendo que a aplicação destes é realizada em todo o sistema de produção do proprietário, inclusive nas hortaliças, contribuindo assim para a melhoria da fertilidade do solo. Isso também pôde ser observado por Oliveira et al. (2001), os quais realizaram um estudo dos efeitos ocasionados destes fertilizantes orgânicos em cultivos de repolho híbrido, e dessa forma obtiveram significativos resultados, tais como a maior produtividade de cabeças de repolho e melhor crescimento da espécie.

No que se diz respeito à questão social, observou-se alguns pontos que precisam ser levados em consideração, como a existência do difícil acesso à saúde, fator que pode ser explicado pela má qualidade das estradas, principalmente em época chuvosa.

Sobre o aspecto político-institucional, observou-se para a execução de todas as atividades que compõem a propriedade, ao longo de sua trajetória no campo, o agricultor participou de poucos treinamentos para aperfeiçoar as técnicas, uma vez que o mesmo conhecimento tradicional e empírico o auxilia nas tomadas de decisões em seu sistema de produção.

Com base nisso, o resultado obtido na somatória dos parâmetros da tabela de indicadores foi equivalente a 121 pontos, visto que grande parte dos indicadores se inseriram nos parâmetros 2 e 3, caracterizados como condições regulares e desejáveis. Sendo assim, o grau de sustentabilidade, de acordo com o método de Guimarães et al. (2015), encontra-se próximo aos níveis de equilíbrio da área, vez que o sistema de produção em estudo é composto por inúmeras práticas agroecológicas.

\section{CONCLUSÕES}

O sistema de produção caracterizado pela agricultura familiar apresentou uma série de aspectos positivos, haja visto, que os objetivos traçados na pesquisa foram alcançados diante do estudo realizado na área.

Por meio da aplicação dos indicadores, foi possível evidenciar tamanha diversidade dos sistemas, que iniciou com poucos cultivos e ao longo dos anos foi sendo aprimorado e implementando novas culturas e técnicas, característica que demonstra o avanço significativo da propriedade. 
As práticas agroecológicas integram o sistema e contribuem para a sustentabilidade próxima ao equilíbrio da área. Dessa forma, é considerada viável economicamente, tendo em vista que a comercialização dos produtos se mostrou lucrativa, assim como o autoconsumo apresentou-se fator determinante na economia monetária do proprietário.

\section{REFERÊNCIAS}

AHRENS, D. C.; MILLÉO, R. D. S.; ZEMKE, E. W.; BENASSI, D.; PELINSKI, A.; CASTRO, A. S.; SANTOS, R. O.; CARVALHO, J. X. A sustentabilidade técnica e socioeconômica de uma propriedade familiar agroecológica em União da Vitória-PR: um estudo de caso. In: CONGRESSO BRASILEIRO DE SISTEMAS DE PRODUÇÃO. 2007.

BORGUI, E.; COSTA, N. V.; CRUSCIOL, C. A. C.; MATEUS, G. P. Influência da distribuição espacial do milho e da brachiaria brizantha consorciados sobre a população de plantas daninhas em sistema plantio direto na palha. Revista Planta Daninha, Viçosa, v. 26, n. 3, p. 559-568, 2008. https://doi.org/10.1590/S0100-83582008000300011

CAPORAL, F. R.; COSTABEBER, J. A. Agroecologia: alguns conceitos e princípios. 1 ed. Brasília: MDA/SAF/DATER-IICA, 2004. Disponível em:

http://www.fca.unesp.br/Home/Extensao/GrupoTimbo/AgroecologiaConceitoseprincipios.pdf

Acesso em: 22 set. 2018.

EHLERS, E. O que é agricultura sustentável. 1. ed. São Paulo: Brasiliense, 2017.Disponível em: https://books.google.com.br/books?hl=ptBR\&lr=\&id=smgvDwAAQBAJ\&oi=fnd\&pg=PT2\&dq=t\%C3 $\%$ A9cnicas+sustent\%C3\%A1veis+na+agricultura+\&ots=IkbF5 Bi1I\&sig=R75EBLKvHX74batx9F00 ubOEqo\#v=onepage\&q=t\%C3\%A9cnicas\%20sustent\%C3\%A1veis\%20na\%20agricultura\&f=false. Acesso em: 02 set. 2018.

EMBRAPA. Sistemas Agroflorestais (SAFs). 2004. Disponível em: https://www.embrapa.br/busca-de-solucoes-tecnologicas/-/produto-servico/112/sistemasagroflorestais-safs. Acesso em: 05 out. 2018.

GALLO, A. S.; GUIMARÃES, N. F.; CUNHA, C.; SANTOS, R. D. P.; CARVALHO, E. M. Indicadores da sustentabilidade de uma propriedade rural de base familiar no estado de Mato Grosso do Sul. Revista Verde de Agroecologia e Desenvolvimento Sustentável, Pombal, v. 11, n. 3, p. 104-114, 2016. https://doi.org/10.18378/rvads.v11i3.4149

GUILHOTO, J. J. M.; ICHIHARA, S. M.; SILVEIRA, F. G.; DINIZ, B. P. C.; AZZONI, C. R.; MOREIRA, G. R. C. A importância da agricultura familiar no Brasil e em seus estados. Brasília: NEAD, 2007.

GUIMARÃES, N. F.; GALLO, A. S.; SANTOS, C. C.; MORINIGO, K. P. G.; BENTOS, A. B.; CARVALHO, E. M. Avaliação da sustentabilidade de um agroecossistema pelo método MESMIS. Scientia Plena, v.11, n.5, p.1-11, 2015.

INSTITUTO DE PESQUISA AMBIENTAL DA AMAZÔNIA. Agricultura no Cerrado ignora clima e viabilidade econômica. 2017. Disponível em: http://ipam.org.br/agricultura-no-cerrado-ignoraviabilidade-economica-e-riscos-climaticos-mostra-analise/. Acesso em: 02 set. 2018.

LAMARCHE, H. A Agricultura familiar: uma realidade multiforme v. I. Campinas: UNICAMP, 1993. 
MASERA, O. R.; ASTIER, M.; LÓPEZ, S. Sustentabilidad y manejo de recursos naturales: el marco de evaluación MESMIS. 1. ed. México: Mundiprensa, GIRA, UNAM, 1999.

MONTEZANO, E. M.; PEIL, R. M. N. Sistemas de consórcio na produção de hortaliças. Revista Brasileira de Agrociência, Pelotas, v. 12, n. 2, p. 129 -132, 2006.

OLIVEIRA, A.F.S. A sustentabilidade da agricultura orgânica familiar dos produtores associados à APOI (Associação dos Produtores Orgânicos da Ibiapaba-CE). 2007. 97 f. Dissertação (Mestrado em Desenvolvimento e Meio Ambiente) Universidade Federal do Ceará, Fortaleza, 2002.

OLIVEIRA, A. P.; FERREIRA, D. S.; COSTA, C. C.; SILVA, A. F.; ALVES, E. U. Uso de esterco bovino e húmus de minhoca na produção de repolho híbrido. Revista Horticultura Brasileira, Brasília, v. 19, n. 01, p. 70-73, 2001. https://doi.org/10.1590/S0102-05362001000100014

OLIVEIRA, A. U. Modo de produção capitalista, agricultura e reforma agrária. 1. ed. São Paulo: FFLCH, 2007. Disponível em:

http://www.gesp.fflch.usp.br/sites/gesp.fflch.usp.br/files/modo capitalista.pdf. Acesso em: 01 set. 2018.

PEROBELLI, F. S.; ALMEIDA, E. S.; ALVIM, M. I. S. A.; FERREIRA, P. G. C. Produtividade do setor agrícola brasileiro (1991-2003): uma análise espacial. Revista Nova economia, Belo Horizonte, v. 17, n. 1, p. 65-91, 2007. https://doi.org/10.1590/S0103-63512007000100003

PREFEITURA MUNICIPAL DE PEDRO GOMES, Geografia. 2018. Disponível em: http://pedrogomes.ms.gov.br/geografia/. Acesso em: 29 set. 2018.

QUANTUM GEOGRAPHIC INFORMATION SYSTEM - QGIS. Software livre que permite a visualização, edição e análise de dados georreferenciados. Fundação Geoespacial de Código Aberto. Versão 2.18.12.

REIS, G. N.; FURLANI, C. E. A.; SILVA, R. P.; GERLACH, J. R.; CORTEZ, J. W.; GROTTA, D. C. C. Decomposição de culturas de cobertura no sistema plantio direto, manejadas mecânica e quimicamente. Revista Engenharia Agrícola, Jaboticabal, v.27, n.1, p.194-200, 2007.

https://doi.org/10.1590/S0100-69162007000100013

RIBEIRO, R. L., SANTOS, C. J., \& DE ALMEIDA, R. S. História do processo de formação da agricultura camponesa no Brasil: resistências e relações de trabalho. Diversitas Journal, v. 3, n. 3, p. 602-622, 2018. https://doi.org/10.17648/diversitas-journal-v3i3.695

RODRIGUES, E. R.; CULLEN JÚNIOR, L.; BELTRAME, T. P.; MOSCOGLIATO, A. V.; SILVA, I. C. Avaliação econômica de sistemas agroflorestais implantados para recuperação de reserva legal no pontal do Paranapanema - São Paulo. Revista Árvore, Viçosa, v.31, n.5, p.941-948, 2007. https://doi.org/10.1590/S0100-67622007000500018

ROEL, A. R. A agricultura orgânica ou ecológica e a sustentabilidade da agricultura. Interações Revista Internacional de Desenvolvimento Local, Campo Grande, v. 3, n. 4, p. 57-62, 2002.

SANTOS, J. G.; CÂNDIDO, G. A. Sustentabilidade e agricultura familiar: um estudo de caso em uma associação de agricultores rurais. Revista de Gestão Social e Ambiental, São Paulo, v. 7, n. 1, p. 70-86, 2013. https://doi.org/10.24857/rgsa.v7i1.528

TEIXEIRA, I. R.; MOTA, J. H.; SILVA, A. G. Consórcio de Hortaliças. Revista Semina: Ciências Agrárias, Londrina, v. 26, n. 4, p. 507-514, 2005. https://doi.org/10.5433/1679-0359.2005v26n4p507 
VENTURA, M. M. O estudo de caso como modalidade de pesquisa. Revista SOCERJ, Rio de Janeiro, v. 20, n. 5, p. 383-386, 2007.

VERONA, L. A. F. Avaliação de sustentabilidade em agroecossistemas de base familiar e em transição agroecológica na região sul do Rio Grande do Sul. 2008. 192f. Tese (Doutorado em Agronomia) - Universidade Federal de Pelotas, Pelotas, 2008.

WANGEN, D. R. B.; FREITAS, I. C. V. Compostagem doméstica: alternativa de aproveitamento de resíduos sólidos orgânicos. Revista Brasileira de Agroecologia, v. 5, n. 2, 2010.

LIMA, M. M. F. Agricultura familiar camponesa no semiárido cearense: o desenvolvimento rural desigual e combinado como corolário da expansão capitalista no campo. Revista Nera, n. 49, p. 271-296, 2019. 